\title{
The Effects of Combined Micron-Scale Surface and Different Nanoscale Features on Cell Response
}

\author{
Yi Kang, ${ }^{1,2}$ Xuelei Ren, ${ }^{1}$ Xin Yuan, ${ }^{1}$ Li Ma ${ }^{1},{ }^{1}$ Youneng Xie, ${ }^{1}$ Zeyu Bian, ${ }^{1}$ Jun Zuo, ${ }^{3}$ \\ Xiyang Wang, ${ }^{4}$ Zhiming Yu, ${ }^{1,4}$ Kechao Zhou, ${ }^{1}$ and Qiuping Wei $\mathbb{D}^{1,4}$ \\ ${ }^{1}$ State Key Laboratory of Powder Metallurgy, School of Materials Science and Engineering, Central South University, \\ Changsha 410083, China \\ ${ }^{2}$ The Third Xiangya Hospital, Central South University, Changsha 410083, China \\ ${ }^{3}$ Xiangya Stomatological Hospital, Central South University, Changsha 410078, China \\ ${ }^{4}$ Hunan Engineering Laboratory of Advanced Artificial Osteo-Materials, Xiangya Hospital, Central South University, \\ Changsha 410078, China
}

Correspondence should be addressed to Li Ma; marycsupm@csu.edu.cn and Qiuping Wei; qiupwei@csu.edu.cn

Received 10 February 2018; Revised 4 May 2018; Accepted 24 May 2018; Published 16 August 2018

Academic Editor: Antonio Riveiro

Copyright (C) 2018 Yi Kang et al. This is an open access article distributed under the Creative Commons Attribution License, which permits unrestricted use, distribution, and reproduction in any medium, provided the original work is properly cited.

Sandblasting and acid-etching (SLA) and anodization are the two most commonly used methods for surface modification of biomedical titanium. However, there are unavoidable problems such as residual sand particles and lack of hydrophilicity on the surface of titanium sheets treated with SLA technology. In addition, titanium implants showed only the micro/submicroscopic structure. In order to avoid the residue of sand particles in the surface of titanium, the two surface treatments etching treatment (E) and etched-anodizing (EA) on titanium were used, and their surface topography, surface chemistry, and surface roughness were compared with those of the SLA control group. Their wettability and the biocompatibility were also compared and evaluated. The results show that both E and EA samples have the micro/nano hierarchical structure and better wettability compared with the SLA samples. Their performances, especially the E surfaces, were enhanced in terms of cell adhesion, spreading, proliferation, and differentiation abilities.

\section{Introduction}

Sandblasting-acid-etching (SLA) is the most commonly used technique for surface treatment of titanium implants. The ITI implant of Straumann company is a representative product of commercial implants, and the microstructural surfaces are obtained through the sandblasting-acid-etching method [1-3]. Sandblasting is a prevalent method to treat titanium. It can increase the surface roughness of the implant [4] and promote the adhesion of osteoblasts [5]. $\mathrm{Al}_{2} \mathrm{O}_{3}$ particles are usually used in the process of sandblasting. However, some sand particles remain on the surface after the acid-etching process. These remaining $\mathrm{Al}_{2} \mathrm{O}_{3}$ particles implanted in vivo would release the toxic $\mathrm{Al}$ ions due to the effect of chemistry and biochemistry [2]. The most direct way to solve this problem is to remove the sandblasting process. However, many studies have shown that, after the removal process in the SLA process, there are many gullies on the surface of the titanium resulting from the simple acidetching process, which leads to the uneven surface of the sample [6-9]. It can be seen that only by removing sandblasting steps, it is difficult to obtain an ideal implant surface in the acid-etching process.

Guo et al. found that replacing $\mathrm{Al}_{2} \mathrm{O}_{3}$ with $\mathrm{SiC}$ during the sandblasting process followed by double-etching can obtain the micro/nanosurface structures and reduce the remaining particles [4]. In addition, hydrophobic amorphous $\mathrm{TiO}_{2}$ will be formed when exposing the fresh etched titanium surface in the air. The surface topography and wettability affect the first stage of osteoblast adhesion, the quality of osseointegration, and protein expression [10-12]. Many studies have shown that the micro/nano hierarchical structure was superior in 
enhancing the biological activity of the titanium surface compared with a single micro- or nanostructure [13-15]. The nanoscale morphology of the implant surface shows obvious advantages in inducing cell proliferation, differentiation, and good bone formation. Therefore, many researchers try to obtain surface implants with micropits by sandblasting-acidetching (SLA) and then use the methods of anodic oxidation [16], double-etching [17], or synthesized nanosheet [18] to prepare nanopores on micro pits, forming a mixed morphology of micron and nano to further enhance their biological activity.

$\mathrm{H}_{2} \mathrm{O}_{2}$ is an excellent oxidant to titanium with clean oxidation products. Xie et al. [19] reported that micro/nano hierarchical structures could be obtained by subsequently immersing SLA-treated titanium samples in $\mathrm{H}_{2} \mathrm{O}_{2}$. Hydrophilic $\mathrm{O}_{2}{ }^{2-}$ was also detected on this surface, which could prohibit bacterial breeding. Furthermore, the sandblast-free double-etching method for titanium surface modification could be used to make surfaces with hierarchical structures and antimicrobial performance, by simply etching titanium in a mixture of $\mathrm{NH}_{3} \cdot \mathrm{H}_{2} \mathrm{O}$, and $\mathrm{H}_{2} \mathrm{O}_{2}$, which had no residual particles [20]. By comparing etching-treated and doubleetching-treated samples, the effects of rough structure in different scales on the MG63 cell were revealed [21].

The anodized implant is also one of the most commonly used commercial implants. The typical representative is the Nobel Biocare implant in Sweden. The surface of the implant showed a crater-like morphology with a hole diameter of $\sim 5 \mu \mathrm{m}$, but there are no nanoscale holes or pits. In fact, by adjusting the voltage of anodic oxidation and changing the reaction time, uniform and dense nano- $\mathrm{TiO}_{2}$ arrays with different sizes can be obtained.

$\mathrm{TiO}_{2}$ nanotubes with different diameters have important effects on gene expression and osseointegration of implants [22]. In order to obtain micro/nanostructures, many methods have been tried, especially the combination of anodic oxidation and other methods, such as silver plasma immersion ion implantation (Ag-PIII) [23], sandblasting and acid-etching [24, 25], and heat treatment [26]. It has been reported that the micro/nanocomposite surface obtained by the composite method could improve the antibacterial properties of the implant [23], the photocatalytic activity [24], the bone deposition [25], the cell response, and the apatite-forming ability [26].

Biocompatibility can be observed and judged by cell attachment, cell proliferation, and differentiation. Generally, microstructures obtained by the acid-etching method usually have good biocompatibility [27], and the nanostructure plays an important role in promoting the attachment of protein and alkaline phosphatase (ALP) [22]. It is reported that the small-sized nanotubes are more conducive to protein adsorption compared with the large-sized ones $[22,28]$. However, the large-sized nanotubes are more suitable for the drug delivery platform [29].

In this study, three surface treatments were used to modify titanium samples. In addition to the traditional sandblasting and acid-etching as group 1 (SLA), titanium samples were etched in a mixture of $\mathrm{H}_{2} \mathrm{O}_{2}$ and $\mathrm{NH}_{4} \mathrm{OH}$ concentrated solutions, namely, $\mathrm{E}$ as group 2, to obtain a hierarchical structure without residual sand particles. Subsequently, $\mathrm{TiO}_{2}$ nanotubes were obtained by anodization as EA group samples, aiming to study the promising surface treatment for titanium implants.

\section{Experimental Details}

2.1. Treatment to Titanium. Firstly, the commercial pure titanium disks (diameter $15 \mathrm{~mm}$ ) were polished and ultrasonically cleaned in acetone, ethanol, and deionized water, respectively. Then, these titanium disks were sandblasted by $\mathrm{Al}_{2} \mathrm{O}_{3}(\phi 250 \sim 500 \mu \mathrm{m})$ at a pressure of $3 \mathrm{~atm}$. And the sandblasting-treated titanium disks were also cleaned in the same way as mentioned above. Subsequently, the treated titanium disks were etched in a boiling mixture of $63 \%$ $\mathrm{H}_{2} \mathrm{SO}_{4}$ and $11 \% \mathrm{HCl}$ solution for 5 minutes. After the samples were removed, ultrasonic cleaning was carried out with ultrapure water 3 times, $10 \mathrm{~min}$ for each time, and then dried in an oven (Heratherm Oven, Thermo Scientific), which was named "SLA."

Samples of group E were ultrasonically etched for 1 hour with a solution containing $\mathrm{H}_{2} \mathrm{O}_{2}$ and $\mathrm{NH}_{4} \mathrm{OH}$. Then, the samples were washed and dried, named as "group 1." In the EA group, the samples etched with mixed $\mathrm{H}_{2} \mathrm{O}_{2}$ and $\mathrm{NH}_{4} \mathrm{OH}$ solution were anodized for $60 \mathrm{~min}$ in the air with a DC power supply (CRS Power, Istanbul, Turkey) at room temperature, with a constant potential of $25 \mathrm{~V}$ and an anodeto-cathode distance of $30 \mathrm{~mm}$ in a $0.5 \mathrm{wt} . \% \mathrm{HF}$ solution.

\subsection{Materials Characterization}

2.2.1. Surface Morphology. In this study, scanning electron microscopy (SEM; Nova NanoSEM 230) was used to observe the surface morphologies of these titanium samples.

2.2.2. Surface Chemistry. The surface chemistry was carried out using X-ray photoelectron spectroscopy (XPS; ESCALAB 250Xi) with Al $\mathrm{K} \alpha$ irradiation. The binding energy for each spectrum was calibrated based on the C1s spectra of $285.0 \mathrm{eV}$.

2.2.3. Surface Roughness. The surface roughness measurement exhibits statistical differences between the roughness values of the samples after treatment. The surface roughness was calculated by the surface profiler (Dektak 150 surface profiler) with each testing line of $1000 \mathrm{~mm}$.

2.2.4. Wettability. The value of contact angle determines whether the surface is hydrophilic or hydrophobic. The surface wettability of materials is generally determined by the contact angle of water. The contact angle was tested by the sessile drop method.

2.3. Cell Culture Assays. MG63 cells (Shanghai Institutes for Biological Sciences, China) were cultured in Dulbecco's modified Eagle's medium (DMEM; Gibco, USA) with 10\% fetal bovine serum (FBS; Gibco, USA) at $37^{\circ} \mathrm{C}$, with $5 \% \mathrm{CO}_{2}$ and $100 \%$ humidity. 

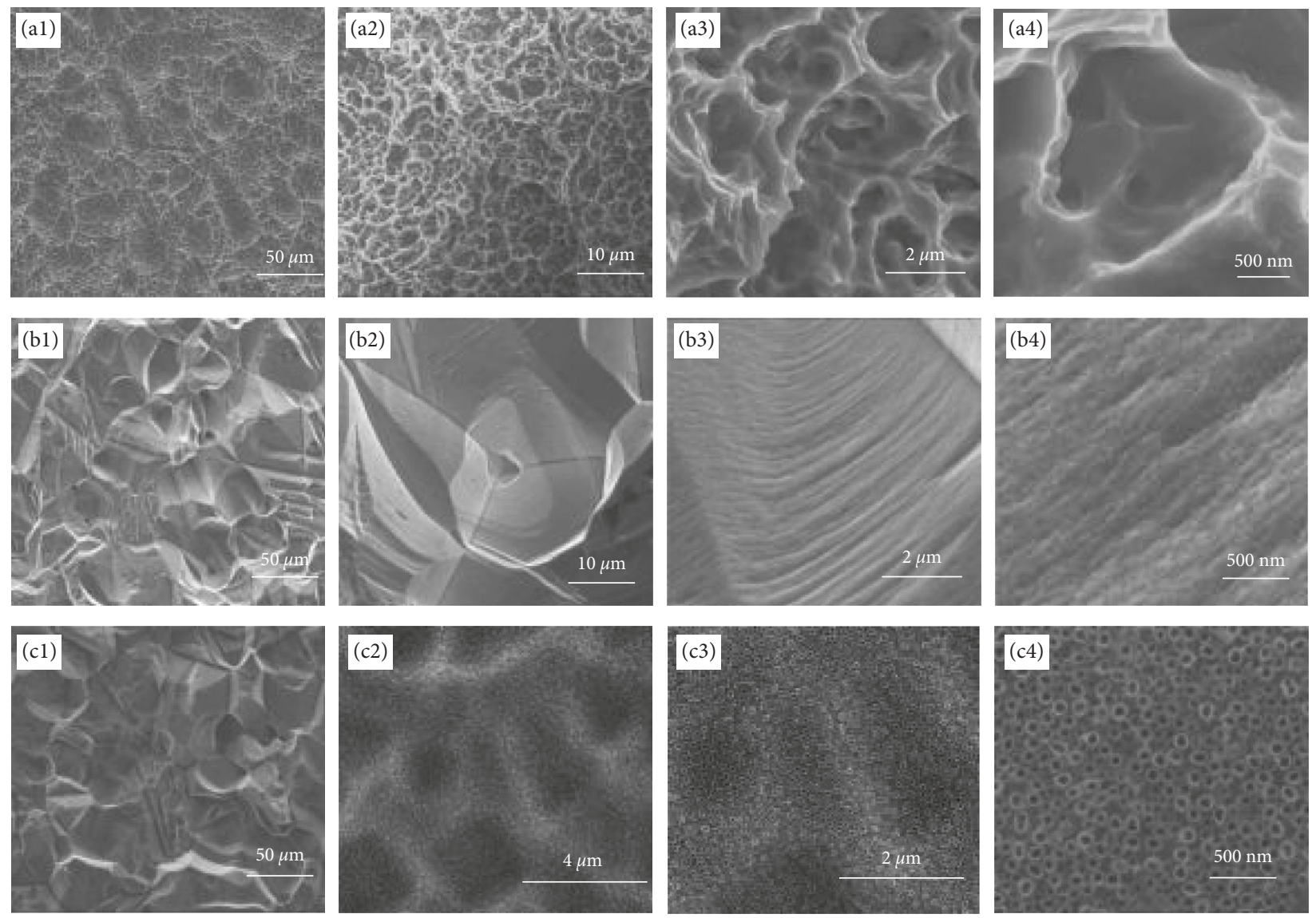

Figure 1: Surface morphologies of SLA (a), E (b), and EA (c) samples.

2.3.1. Cell Adhesion and Spread. MG63 cells were seeded on 24-well plates with a density of $2 \times 10^{4}$ per well on each group. After culturing for $4 \mathrm{~h}$, the cells were rinsed by buffer solution (PBS) to clear nonadherent cells. The attached cells were fixed in $4 \%$ paraformaldehyde (Sigma, USA) for 15 minutes. And then cells were dyed by AO for 10 minutes, and fluorescence was measured. In order to detect the area of cells, the attached cells were fixed in $4 \%$ paraformaldehyde (Sigma, USA) for 15 minutes and dyed by phalloidin for $1 \mathrm{~h}$, and fluorescence was measured and analyzed by Image J.

2.3.2. Cell Proliferation and Vitality. MG63 cells were seeded on 24-well plates with a density of $2 \times 10^{4}$ per well on each group. After culturing for $24 \mathrm{~h}, 48 \mathrm{~h}$, and $72 \mathrm{~h}$, the cell numbers were counted by an automatic cell counter. Cell vitality was detected by the method of CCK-8.

2.3.3. Cell Differentiation. MG63 cells were seeded on 24well plates with a density of $7 \times 10^{4}$ per well on four groups, and the activity of alkaline phosphatase (ALP) was determined on the 7th and 14th days of osteoinduction. The level of ALP was normalized to total protein content at the end of the experiment.

The expression levels of osteogenic-related genes, Runx2 and OCN, were detected on 7 days of osteoinduction. The image adoption was performed using the Gel Doc XR system (Bio-Rad, USA).

2.4. Statistical Analysis. Data from experiments examining cell assays of the substrates are presented as the mean error and standard deviation of the mean error of all the measurements performed on different samples. Data were evaluated by analysis of significant differences among different groups, which were determined using two-way ANOVA by "GraphPad Prism." Asterisk (*) represents significant differences between different substrates $(P<0.05)$.

\section{Results}

3.1. Surface Morphology. The SEM images of SLA, E, and EA samples are shown in Figure 1. It could be seen that a hierarchical microscale structure has a hole diameter of around $20 \mu \mathrm{m}$ and $1-2 \mu \mathrm{m}$. As shown in Figure 1(a4), the edges of these holes were sharp, and the walls were smooth. The images (Figures 1(a1)-1(a4)) showed a typical SLA morphology without nanostructures.

After being etched by $\mathrm{H}_{2} \mathrm{O}_{2}$ and $\mathrm{NH}_{4} \mathrm{OH}$ solution, the $\mathrm{E}$ and EA samples had a similar surface topography on the microscale with about $20 \mu \mathrm{m}$ holes (Figures 1(b1) and 1(c1)). Under higher magnification, fluctuant textures were found in the walls of holes (Figure 1(b3)). Many nanopits were 

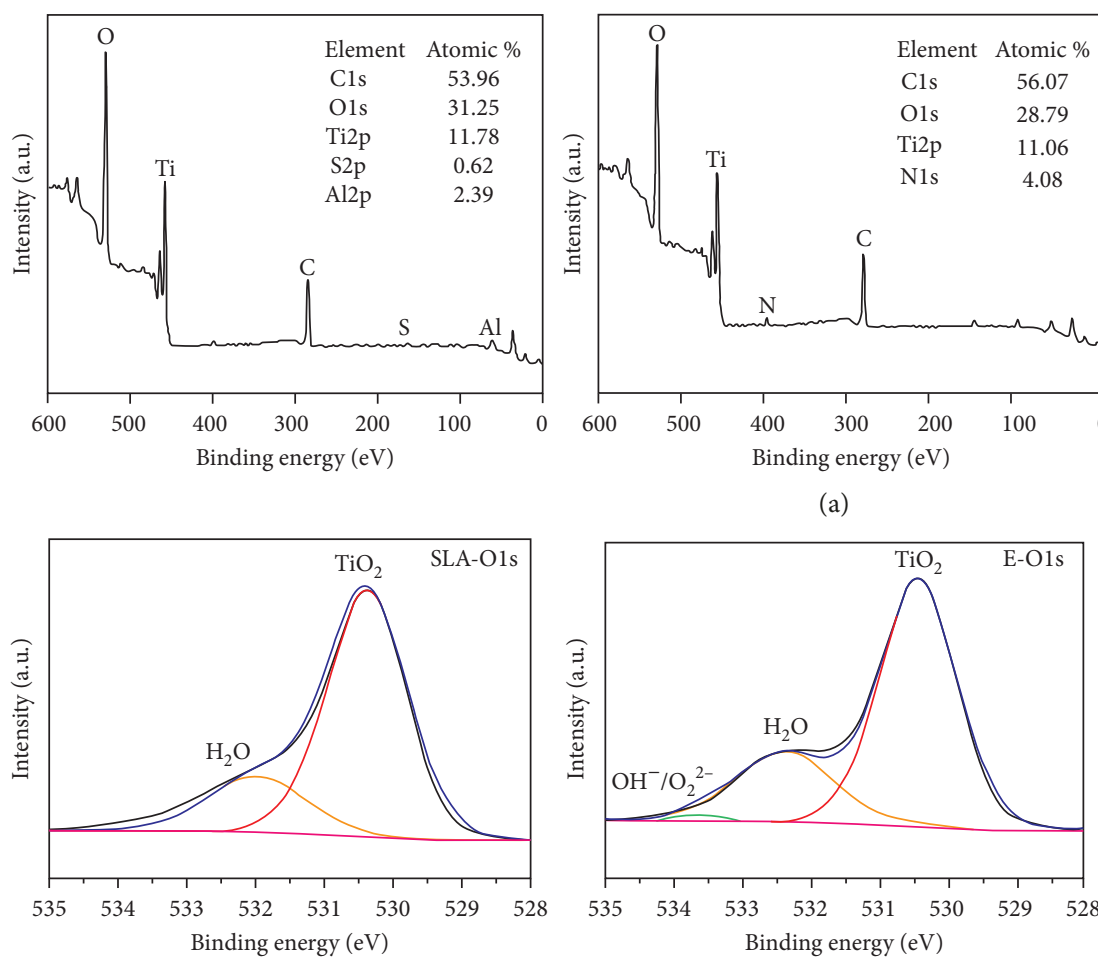

(b)
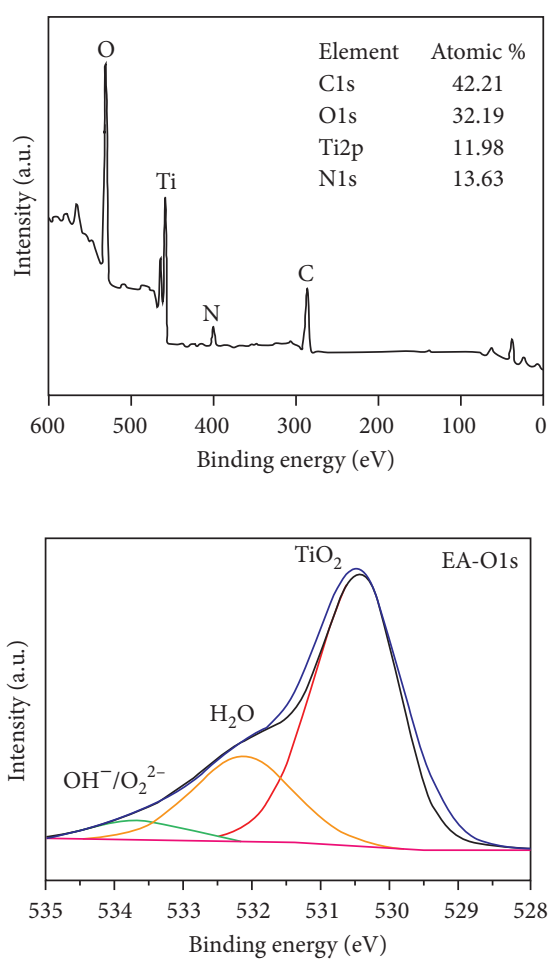

FIgURE 2: XPS survey spectra of SLA, E, and EA surfaces (a); XPS narrow spectra of O1s on SLA, E, and EA surfaces (b).

observed on the lamellar structures when it comes to nanoscale (Figure 1(b4)). Unlike E, EA surfaces exhibited many nanotubes, rather than wave-like structures, in the walls and the edges of holes (Figures 1(c2) and 1(c3)). The average diameter of these nanotubes was about $100 \mathrm{~nm}$ (Figure 1(c4)).

3.2. Surface Chemistry. The results of the XPS spectra are displayed in Figure 2. They were mainly composed of the three elements $\mathrm{Ti}, \mathrm{C}$, and $\mathrm{O}$. The $\mathrm{Al}$ element on the surface of SLA-treated samples came from the residual $\mathrm{Al}_{2} \mathrm{O}_{3}$ sand particles. $\mathrm{N}$ was observed in both $\mathrm{E}$ and $\mathrm{EA}$ samples. The etching process would remain a part of $\mathrm{N}$ because of the presence of $\mathrm{NH}_{4} \mathrm{OH}$ in the mixed solution. In addition, the concentration of $\mathrm{N}$ on EA samples was higher than that on $\mathrm{E}$ samples, which could be attributed to $\mathrm{NH}_{4} \mathrm{~F}$ in the electrolyte.

Figure 2 is the O1s spectra of the three surfaces. It could be seen from the results that the binding energy values corresponding to these peaks of the SLA surface were $530.2 \mathrm{eV}$ and $532 \mathrm{eV}$. According to the NIST XPS Database, the peak at $530.2 \mathrm{eV}$ represents the peak of $\mathrm{O}^{2-}$ in $\mathrm{TiO}_{2}$ and the peak at $532 \mathrm{eV}$ represents $\mathrm{O}^{2-}$ in $\mathrm{H}_{2} \mathrm{O}$. The binding energy values corresponding to these peaks of $\mathrm{E}$ and $\mathrm{EA}$ surfaces were $530.2 \mathrm{eV}, 532 \mathrm{eV}$, and $533.6 \mathrm{eV}$, respectively. The peak at $\sim 533.6 \mathrm{eV}$ of the $\mathrm{E}$ surface could be $\mathrm{O}_{2}{ }^{2-}$ in $\mathrm{Ti}\left(\mathrm{H}_{2} \mathrm{O}_{2}\right)_{2}{ }^{4+}$, which might be produced in the etching process of $\mathrm{H}_{2} \mathrm{O}_{2}$ and $\mathrm{NH}_{4} \mathrm{OH}$ solution. The peak at $533.6 \mathrm{eV}$ of the EA surface could also be $\mathrm{O}_{2}{ }^{2-}$, which might be formed in both the etching and anodization processes. However, $\mathrm{O}_{2}{ }^{2-}$ is not stable and easy to resolve. Consequently, it could also turn to $\mathrm{OH}^{-}$.
3.3. Surface Roughness. Figure 3 shows the results of surface roughness detected by the profilometer. The results indicated that the average surface roughness of SLA was $2.4 \mu \mathrm{m}$, which was close to the standard of the ITI implant $(\mathrm{Ra}=2.5 \mu \mathrm{m})$. The surface roughnesses of $\mathrm{E}$ and EA samples were $3.2 \mathrm{~mm}$ and $5.8 \mathrm{~mm}$, respectively.

3.4. Surface Wettability. The surface contact angles of fresh surfaces and exposed surfaces are shown in Figure 4. For SLA, E, and EA, the contact angles of fresh surfaces are $42^{\circ}$, $30^{\circ}$, and $53^{\circ}$, respectively, showing hydrophilicity. After exposure to air for 7 days, the contact angles of SLA and E increased significantly to $123^{\circ}$ and $120^{\circ}$. The contact angle of EA also increased to $90^{\circ}$, showing a good wettability to maintain good hydrophilicity.

3.5. Cell Adhesion and Cell Spread. Figure 5 shows the average area and number of MG63 cells attached to three substrates after culturing for 4 hours. Differences in cell morphologies are observed in Figure 5(a). The cells spread more on the E surface, and the shape of the cells was outspread, indicating that the cells grew. However, the cells on the SLA and EA surfaces kept round shape mostly.

The data of three samples showed significant differences $(P<0.05)$. Counting and analyzing the number of cells, the results revealed that the number of $E$ cells was the largest and that the difference among substrates was significant $(P<0.001$ for E and SLA and $P<0.01$ for E and EA $)$. 


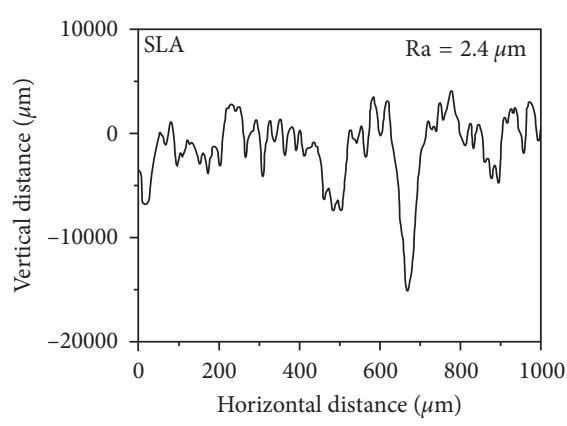

(a)

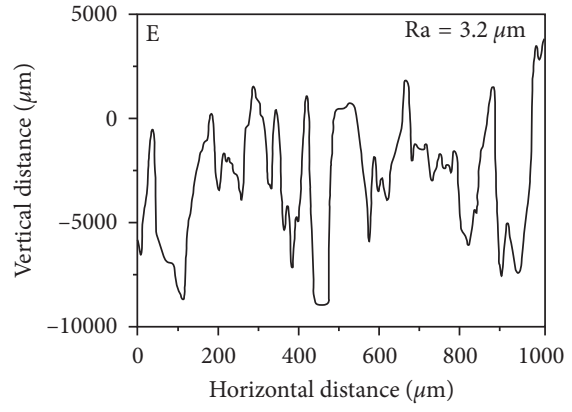

(b)

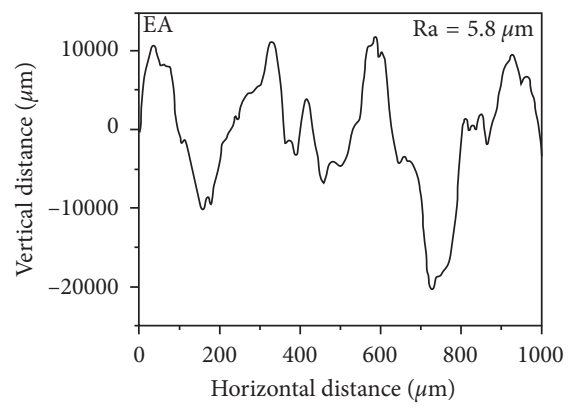

(c)

Figure 3: Surface roughness of SLA (a), E (b), and EA (c) surfaces.

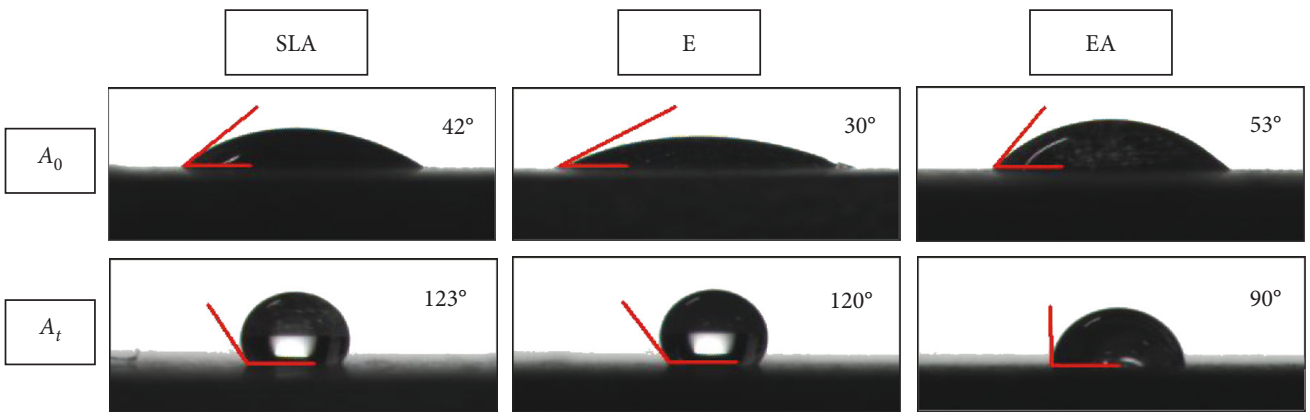

FIgURE 4: Water contact angles on SLA, E, and EA fresh surfaces $\left(A_{0}\right)$ and exploded surfaces for 7 days $\left(A_{t}\right)$.
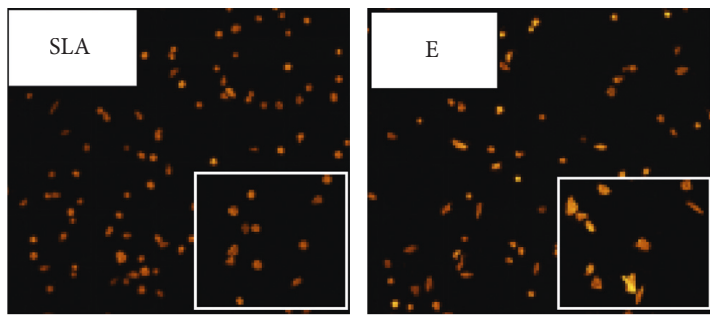

(a)
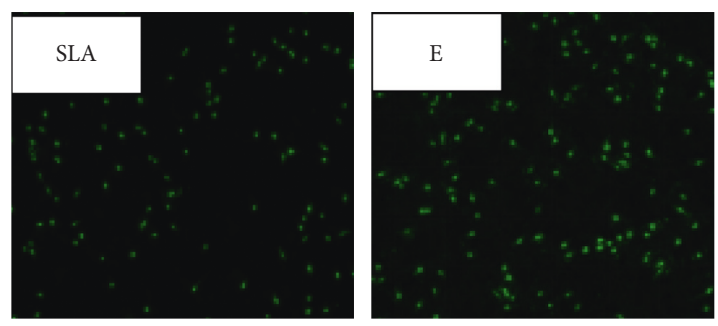

(c)
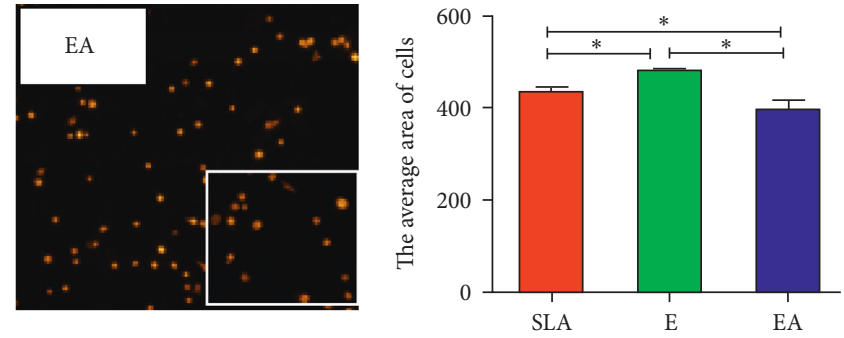

(b)
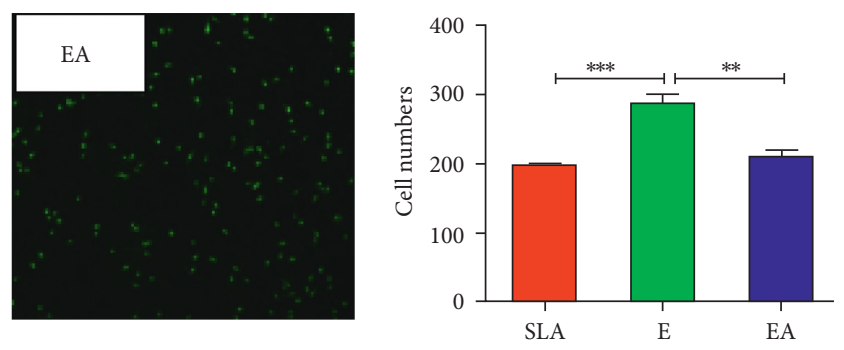

(d)

Figure 5: Attached cell average areas $(a, b)$ and numbers $(c, d)$ of MG63 cells cultured on each group of surfaces for 4 h.

3.6. Cell Proliferation and Cell Vitality. Cell proliferation is shown in Figure 6(a). In the early cell culture for $24 \mathrm{~h}$ and $48 \mathrm{~h}$, the number of cells in the three samples was nearly close, and there was no significant difference among them. At $72 \mathrm{~h}$, it showed a significant increase in three substrates, especially E samples. The cells of EA samples were slightly higher than those of SLA samples. The cell vitality was measured by the
CCK-8 assay. From the results, E had the most excellent cell vitality, no matter in what time. The cell vitality on SLA increased a lot in the early $48 \mathrm{~h}$ and tended to be stable at $72 \mathrm{~h}$. In contrast, the cell vitality on EA increased slightly in the early $48 \mathrm{~h}$, while it increased significantly in $72 \mathrm{~h}$. The results revealed that both $\mathrm{E}$ and $\mathrm{EA}$ surfaces provided a more suitable and superior environment for cell proliferation. 


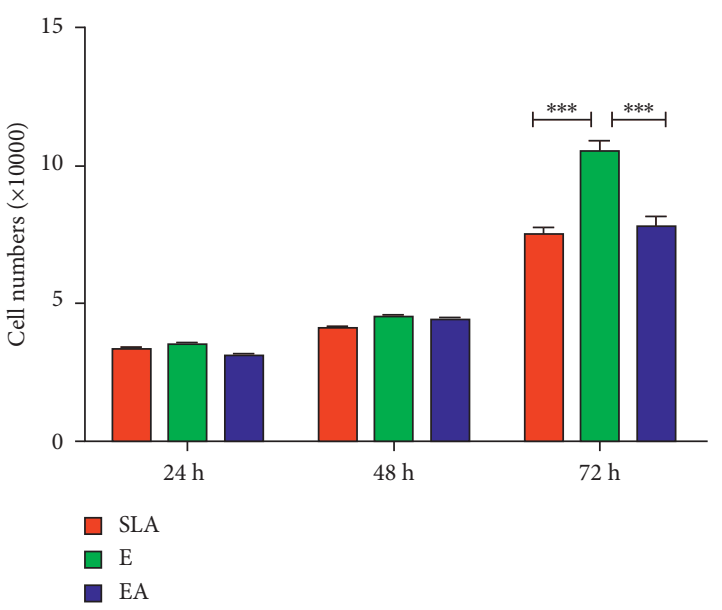

(a)

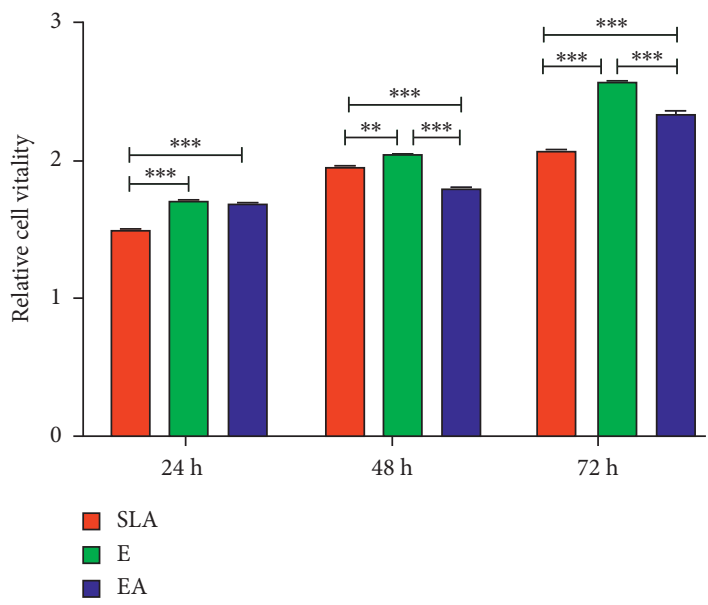

(b)

Figure 6: Cell numbers after culturing for 24,48 , and $72 \mathrm{~h}$ (a) and cell viability after culturing for 24,48 , and $72 \mathrm{~h}(\mathrm{~b})\left({ }^{*} P<0.05\right.$; ${ }^{* *} P<0.01$; *** $P<0.001)$

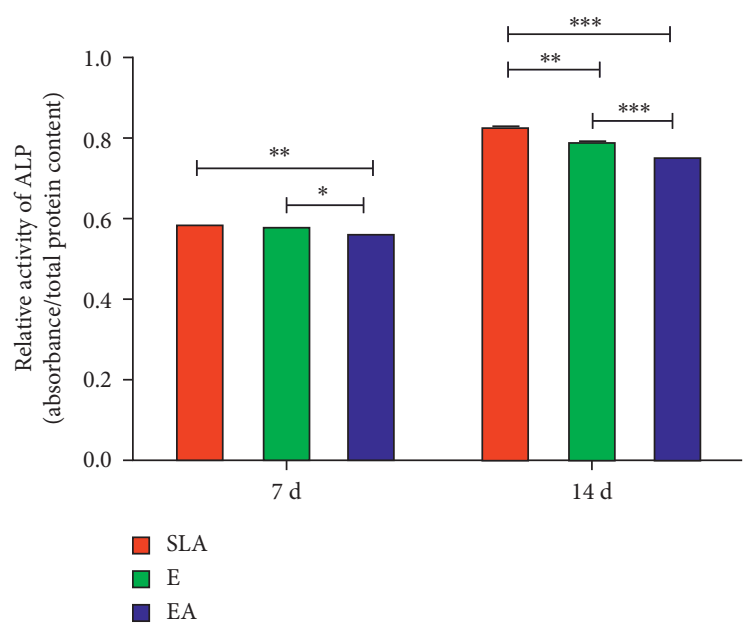

(a)

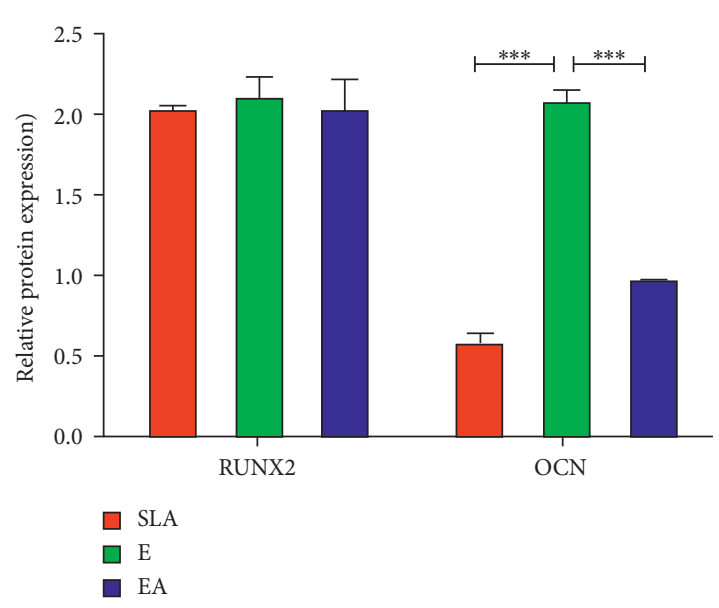

(b)

FIgURE 7: Relative activity of ALP after culturing for $7 \mathrm{~d}$ and $14 \mathrm{~d}$ of osteoinduction (a) and OCN and RUNX2 production on the 7th day of osteoinduction (b) $\left({ }^{*} P<0.05 ;{ }^{* *} P<0.01 ;{ }^{* * *} P<0.001\right)$.

3.7. Cell Differentiation. Figure 7(a) shows the results of the ALP assay. The ALP activity of MG63 cells on all samples increased as the culturing time increased. After culturing for 7 days, the results of all samples were nearly close, and SLA had a slight advantage over the others.

After culturing for 14 days, the SLA surface demonstrated the highest ALP activity, followed by the E surface and then the EA surface. Figure 7(b) shows the results of RUNX2 and $\mathrm{OCN}$ assays. The E surface also showed significantly higher expression of RUNX2 and OCN compared with SLA and EA surfaces. And there was a significant difference among the SLA group, the EA group, and the E group $(P<0.001)$.

\section{Discussion}

Three different kinds of surface-treated methods, sandblasting and acid-etching (SLA), etching by $\mathrm{H}_{2} \mathrm{O}_{2}$ and $\mathrm{NH}_{4} \mathrm{OH}$ solution (E), and etching and anodization (EA), were used to prepare pure titanium samples with different surface morphologies. Their surface topography, surface chemistry composition, surface roughness, wettability, and MG63 cell response about cell attachment including proliferation, vitality, and differentiation by each method were compared. E and EA samples had similar microstructures, but nanostructures were different. The diameters of nanotubes on the EA surface can be changed from 20 to $100 \mathrm{~nm}$ by changing the voltage of anodization to meet various requirements, such as the drug platform and delivery [30]. The O1s spectra of E and EA samples revealed the possible existence of ROS. It has been reported that the cell vitality on surfaces modified by anodization was better than that of untreated ones [31]. Researchers attributed this to the existence of ROS. Additionally, it was found that the treated surface with ROS was antibacterial and hydrophilic [32]. 


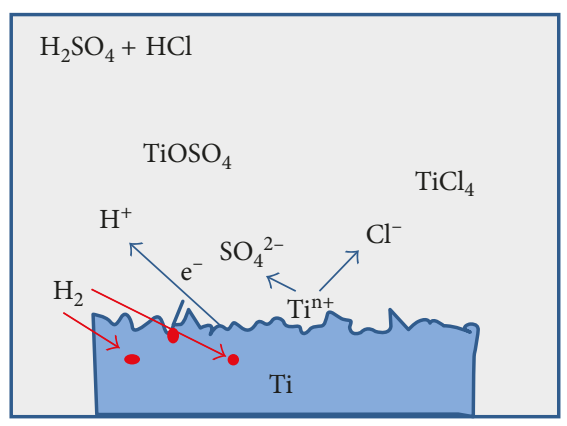

(a)

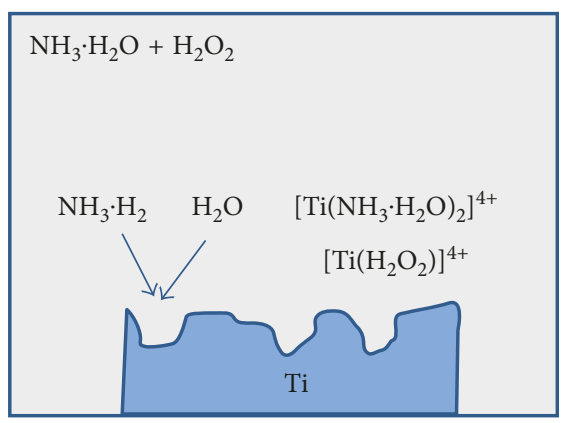

(b)

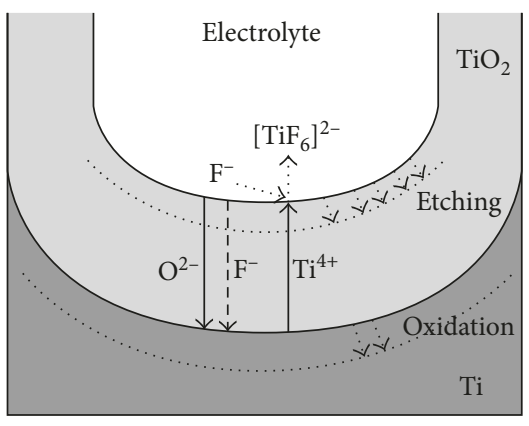

(c)

FIgURE 8: The corrosion mechanisms of $\mathrm{H}_{2} \mathrm{SO}_{4}+\mathrm{HCl}$ (a), $\mathrm{NH}_{4} \mathrm{OH}+\mathrm{H}_{2} \mathrm{O}_{2}$ (b), and anodization (c).

The surface roughness of the implant also affected the formation of the bone. Generally, moderate roughness remarkably exhibited enhanced bone osseointegration.

The best surface roughness of the implant was considered as $1 \sim 2 \mu \mathrm{m}$, followed by $>2 \mu \mathrm{m}$. The results showed that the surface of modified titanium samples and SLA belonged to the rough implant group, which might contribute to cell adhesion.

The wettability is an important factor for cell adhesion, and its importance is almost the same as that of surface topography [33]. The existence of ROS and nanostructures might contribute to the better wettability of the fresh titanium surface [10,32, 34]. After exposure to air for 7 days, the EA sample showed better wettability than the others. Usually, the fresh titanium surface could be contaminated by $\mathrm{C}$ in the air, resulting in a decrease of wettability. After being treated with the controlled anodizing method, a selforganized and highly ordered coating of $\mathrm{Ti}$ and Ti-based alloys, namely, the $\mathrm{TiO}_{2}$ nanotube film, was produced. This $\mathrm{TiO}_{2}$ film protects the EA surface from this kind of pollution.

The surface topography and surface chemical composition of the three groups of titanium samples have changed. The results showed that the influence of surface treatment on cell compatibility might come from two aspects: one aspect is linked to the existence of ROS on the surface of the material. Oxygen species on surfaces could improve initial fixation and wettability of titanium, which facilitates cell adhesion [2,35]. The other aspect is that nanoscale roughness can significantly affect cell adhesion [36], proliferation [37], and spreading [38]. The cell adhesion and spreading results indicated that both $\mathrm{E}$ and EA titanium surfaces promoted the early attachment and spreading of osteoblasts. E and EA surfaces offered a favorable environment for osteoblasts to extend more pseudopodia than that on SLA surfaces. Cell proliferation, which is an important mark of the cell growth, is closely connected with cell adhesion. From the results, the modified titanium surfaces had higher initial cell numbers, indicating a significant promotion in cell proliferation. For cell adhesion and proliferation abilities, it seemed that nanostructures counted more.

Osteoblasts responded synergistically to the micro/ nanostructured surfaces in terms of cell proliferation and local factor production [39]. The number of cells and the productions of OCN and RUNX2 on micro/nanostructured surfaces (E and EA) after 7 days of osteoinduction were higher than those on the micron/submicron-structured surface
(SLA). This indicated that the nanostructure plays an important role in cell differentiation. Recent studies have shown that the interaction between cells and nanotopography surfaces could lead to the modulation of mechanotransduction and improve the cell proliferation $[40,41]$. In this study, nanostructured E and EA surfaces showed better cell response. For comparison of E and EA, the surface of EA consists of about $100 \mathrm{~nm}$ nanotubes instead of nanopits. Although EA samples had micro/nanostructure and better wettability when stored in atmosphere, the results of cell adhesion and proliferation were not superior to those of $\mathrm{E}$ specimens. One possible explanation could be that $\mathrm{TiO}_{2}$ nanotubes could control cell fate and interfacial osteogenesis by altering their nanoscale dimension. It was reported that the adhesion and differentiation abilities of bone marrow mesenchymal stem cells (BMMSCs) on $\mathrm{TiO}_{2}$ nanotubes were related to the nanotube dimension [42]. It has been suggested that a $70 \mathrm{~nm}$ nanotube is the optimum size for $\mathrm{TiO}_{2}$ nanotube implants to obtain a favorable osteoconductivity and osseointegration $[22,43]$. However, the diameter of nanotubes in this study was nearly $100 \mathrm{~nm}$. Therefore, a more suitable nanotube dimension is needed to be explored in the following research.

The corrosion mechanisms of three different methods were also considered, and their corrosion mechanisms were schematically described in Figure 8 [44]. Microholes were formed in $\mathrm{E}$ and SLA. $\mathrm{NH}_{4} \mathrm{OH}$ and $\mathrm{H}_{2} \mathrm{O}_{2}$ with strong coordinative capability etched titanium rapidly at the boundaries and formed very huge and deep holes. $\mathrm{H}_{2} \mathrm{SO}_{4}$ and $\mathrm{HCl}$ can form many complex compounds with titanium and impurities and directly etch titanium in both the boundaries and facet, leading to different micron-scale surfaces. The surface of SLA has a peak and valley morphology which is easy to produce defects, while the surface of $\mathrm{E}$ has a hole pit morphology with a larger curvature and has a relatively smooth and flat hole wall, which is beneficial to anodized nanotube composites. And the surface of EA shows a micromorphology compounded with nanotubes well. The combined micromorphology and nanotube surface has a good biocompatibility and a large clearance space proportion for drug delivery. It deserves more research for application in the future.

In this study, we chose the traditional SLA implants-the most prevalent commercial titanium implants-as a control group. The results showed that two kinds of sandblast-free 
modified titanium implants (E and EA) showed better bioactivity because of their micro/nanostructures and wettability. Although EA samples had the micro/nanostructures and the possible existence of ROS, they do not show the best advantage in cell proliferation and differentiation. The exact cause and mechanism of the micro/nanostructured surface in the effect of the osseointegration still require further research.

\section{Conclusions}

In this study, a new and simple method (E) for titanium implants was proposed. The hierarchical micro/nanostructured surfaces without residual sand particles were obtained by $\mathrm{E}$ treatment. The cell adhesion, proliferation, vitality, and osteogenic differentiation were enhanced on the surfaces of $\mathrm{E}$ samples cultured by MG63 cells.

Another simple modification process (EA) was also developed. The nanotube was stacked on the micron-scale surface of the Ti sample. Good biocompatibility and larger clearance space proportion were obtained. It might have a promising future for drug delivery application.

\section{Data Availability}

The data used to support the findings of this study are available from the corresponding author upon request.

\section{Conflicts of Interest}

The authors declare that they have no conflicts of interest.

\section{Acknowledgments}

This study was supported by the National Natural Science Foundation of China (no. 51601226), the National Key Research and Development Program of China (no. 2016YEB0301402), the Open-End Fund for the Valuable and Precision Instruments of Central South University, and the project supported by the State Key Laboratory of Powder Metallurgy, Central South University, Changsha, China.

\section{References}

[1] S. B. Li, J. Ni, X. Liu et al., "Surface characteristics and biocompatibility of sandblasted and acid-etched titanium surface modified by ultraviolet irradiation: an in vitro study," Journal of Biomedical Materials Research Part B Applied Biomaterials, vol. 100, no. 6, pp. 1587-1598, 2012.

[2] R. A. Gittens, R. Olivaresnavarrete, A. Cheng et al., "The roles of titanium surface micro/nanotopography and wettability on the differential response of human osteoblast lineage cells.," Acta Biomaterialia, vol. 9, no. 4, pp. 6268-6277, 2013.

[3] I. S. Yeo, "Reality of dental implant surface modification: a short literature review," Open Biomedical Engineering Journal, vol. 8, no. 8, pp. 114-119, 2014.

[4] C. Y. Guo, J. P. Matinlinna, and A. T. Tang, "Effects of surface charges on dental implants: past, present, and future," International Journal of Biomaterials, vol. 2012, Article ID 381535, 5 pages, 2012.
[5] K. Anselme, "Osteoblast adhesion on biomaterials," Biomaterials, vol. 21, no. 7, pp. 667-681, 2000.

[6] Z. Qu, X. Rausch-Fan, M. Wieland, M. Matejka, and A. Schedle, "The initial attachment and subsequent behavior regulation of osteoblasts by dental implant surface modification," Journal of Biomedical Materials Research Part A, vol. 82, no. 3, pp. 658-668, 2007.

[7] F. Rupp, L. Scheideler, N. Olshanska, M. de Wild, M. Wieland, and J. Geis-Gerstorfer, "Enhancing surface free energy and hydrophilicity through chemical modification of microstructured titanium implant surfaces," Journal of Biomedical Materials Research Part A, vol. 76, no. 2, pp. 323-334, 2006.

[8] X. Rausch-Fan, Z. Qu, M. Wieland, M. Matejka, and A. Schedle, "Differentiation and cytokine synthesis of human alveolar osteoblasts compared to osteoblast-like cells (MG63) in response to titanium surfaces," Dental Materials, vol. 24, no. 1, pp. 102-110, 2008.

[9] G. L. Yang, F. M. He, X. F. Yang, X. X. Wang, and S. F. Zhao, "Bone responses to titanium implants surface-roughened by sandblasted and double etched treatments in a rabbit model," Oral Surgery, Oral Medicine, Oral Pathology, Oral Radiology, and Endodontology, vol. 106, no. 4, pp. 516-524, 2008.

[10] Y. Shibata and Y. Tanimoto, "A review of improved fixation methods for dental implants. Part I: surface optimization for rapid osseointegration," Journal of Prosthodontic Research, vol. 59, no. 1, pp. 20-33, 2015.

[11] D. Khang, J. Lu, C. Yao, K. M. Haberstroh, and T. J. Webster, "The role of nanometer and sub-micron surface features on vascular and bone cell adhesion on titanium," Biomaterials, vol. 29, no. 8, pp. 970-983, 2008.

[12] R. A. Gittens, R. Olivaresnavarrete, Z. Schwartz et al., "Implant osseointegration and the role of microroughness and nanostructures: lessons for spine implants," Acta Biomaterialia, vol. 10, no. 8, pp. 3363-3371, 2014.

[13] H. Liu and T. J. Webster, "Nanomedicine for implants: a review of studies and necessary experimental tools," Biomaterials, vol. 28, no. 2, pp. 354-369, 2007.

[14] G. Mendonça, D. B. S. Mendonça, F. J. L. Aragão, and L. F. Cooper, "Advancing dental implant surface technology-from micron- to nanotopography," Biomaterials, vol. 29, no. 28, pp. 3822-3835, 2008.

[15] B. S. Moon, S. W. Kim, H. E. Kim, and T. S. Jang, "Hierarchical micro-nano structured Ti6Al4V surface topography via two-step etching process for enhanced hydrophilicity and osteoblastic responses," Materials Science and Engineering: $C$, vol. 73, pp. 90-98, 2017.

[16] S. A. Yavari, J. van der Stok, Y. C. Chai et al., "Bone regeneration performance of surface-treated porous titanium," Biomaterials, vol. 35, no. 24, pp. 6172-6181, 2014.

[17] E. S. Ogawa, A. O. Matos, T. Beline et al., "Surface-treated commercially pure titanium for biomedical applications: electrochemical, structural, mechanical and chemical characterizations," Materials Science and Engineering. C, Materials for Biological Applications, vol. 65, pp. 251-261, 2016.

[18] S. Shao, P. Ming, J. Qiu et al., "Modification of a SLA titanium surface with calcium-containing nanosheets and its effects on osteoblast behavior," RSC Advances, vol. 7, no. 11, pp. 6753-6761, 2017.

[19] Y. Xie, J. Li, Z. M. Yu et al., "Nano modified SLA process for titanium implants," Materials Letters, vol. 186, pp. 38-41, 2016.

[20] Y. Xie, J. Zuo, B. Zhou et al., "Sandblast-free double-etched titanium for dental implants application," Materials Letters, vol. 176, pp. 74-77, 2016. 
[21] J. Zhang, Y. Xie, J. Zuo et al., "Cell responses to titanium treated by a sandblast-free method for implant applications," Materials Science and Engineering C, vol. 78, pp. 1187-1194, 2017.

[22] N. Wang, H. Li, W. Lü et al., "Effects of $\mathrm{TiO}_{2}$, nanotubes with different diameters on gene expression and osseointegration of implants in minipigs," Biomaterials, vol. 32, no. 29, pp. 6900-6911, 2011.

[23] S. Mei, H. Wang, W. Wang et al., "Antibacterial effects and biocompatibility of titanium surfaces with graded silver incorporation in titania nanotubes," Biomaterials, vol. 35, no. 14, pp. 4255-4265, 2014.

[24] D. Tuncay, D. Selim, and E. Mustafa, "Enhanced photocatalytic activity of micro/nano textured $\mathrm{TiO}_{2}$ surfaces prepared by sandblasting/acid-etching/anodizing process," Journal of Alloys and Compounds, vol. 694, pp. 246-252, 2017.

[25] K. L. Ou, H. J. Hsu, T. S. Yang, Y. H. Lin, C. S. Chen, and P. W. Peng, "Osseointegration of titanium implants with SLAffinity treatment: a histological and biomechanical study in miniature pigs," Clinical Oral Investigations, vol. 20, no. 7, pp. 1515-1524, 2016.

[26] S. Bsat, S. Yavari, M. Munsch, E. Valstar, and A. Zadpoor, "Effect of alkali-acid-heat chemical surface treatment on electron beam melted porous titanium and its apatite forming ability," Materials, vol. 8, no. 4, pp. 1612-1625, 2015.

[27] A. Wennerberg, "The importance of surface roughness for implant incorporation," International Journal of Machine Tools and Manufacture, vol. 38, no. 5-6, pp. 657-662, 1998.

[28] L. W. Lv, Y. S. Liu, and P. Zhang, "The nano scale geometry of $\mathrm{TiO}_{2}$ nanotubes influences the osteogenic differentiation of human adipose-derived stem cells by modulating H3K4 trimethylation," Biomaterials, vol. 39, pp. 193-205, 2015.

[29] Q. L. Ma, L. Z. Zhao, and R. R. Liu, "Improved implant osseointegration of a nano structured titanium surface via mediation of macrophage polarization," Biomaterials, vol. 35, pp. 9853-9867, 2014.

[30] L. Shi, H. Xu, X. Liao et al., "Fabrication of two-layer nanotubes with the pear-like structure by an in-situ voltage up anodization and the application as a drug delivery platform," Journal of Alloys and Compounds, vol. 647, no. 1, pp. 590-595, 2015.

[31] S. Omori, Y. Shibata, T. Arimoto, T. Igarashi, K. Baba, and T. Miyazaki, "Micro-organism and cell viability on antimicrobially modified titanium," Journal of Dental Research, vol. 88, no. 10, pp. 957-962, 2009.

[32] Y. Shibata, D. Suzuki, S. Omori et al., "The characteristics of in vitro biological activity of titanium surfaces anodically oxidized in chloride solutions," Biomaterials, vol. 31, no. 33, pp. 8546-8555, 2010.

[33] A. G. I. Rolando, T. Mclachlan, R. Olivares-Navarrete et al., "The effects of combined micron-/submicron-scale surface roughness and nanoscale features on cell proliferation and differentiation," Biomaterials, vol. 32, no. 13, pp. 3395-3403, 2011.

[34] M. Iwai-Yoshida, Y. Shibata, Wurihan et al., "Antioxidant and osteogenic properties of anodically oxidized titanium," Journal of the Mechanical Behavior of Biomedical Materials, vol. 13, no. 9, pp. 230-236, 2012.

[35] H. Aita, N. Hori, M. Takeuchi et al., "The effect of ultraviolet functionalization of titanium on integration with bone," Biomaterials, vol. 30, no. 6, pp. 1015-1025, 2009.

[36] M. J. Biggs, R. G. Richards, N. Gadegaard et al., "Interactions with nanoscale topography: adhesion quantification and signal transduction in cells of osteogenic and multipotent lineage," Journal of Biomedical Materials Research Part A, vol. 91, no. 1, pp. 195-208, 2010.

[37] E. Palin, H. Liu, and T. J. Webster, "Mimicking the nanofeatures of bone increases bone-forming cell adhesion and proliferation," Nanotechnology, vol. 16, no. 9, pp. 1828-1835, 2005.

[38] M. J. Dalby, D. Mccloy, M. Robertson, C. D. W. Wilkinson, and R. O. C. Oreffo, "Osteoprogenitor response to defined topographies with nanoscale depths," Biomaterials, vol. 27, no. 8, pp. 1306-1315, 2006.

[39] R.A. Gittens, T. McLachlan, R. Olivares-Navarrete et al., "The effects of combined micron-/submicron-scale surface roughness and nanoscale features on cell proliferation and differentiation," Biomaterials, vol. 32, no. 13, pp. 3395-3403, 2011.

[40] H. N. Kim, A. Jiao, N. S. Hwang et al., "Nanotopographyguided tissue engineering and regenerative medicine," Advanced Drug Delivery Reviews, vol. 65, no. 4, pp. 536-548, 2013.

[41] K. Kulangara, Y. Yang, J. Yang, and K. W. Leong, "Nanotopography as modulator of human mesenchymal stem cell function," Biomaterials, vol. 33, no. 20, pp. 4998-5003, 2012.

[42] W. Yu, C. Qian, X. Jiang, F. Zhang, and W. Weng, "Mechanisms of stem cell osteogenic differentiation on $\mathrm{TiO}_{2}$ nanotubes," Colloids and Surfaces B Biointerfaces, vol. 136, pp. 779-785, 2015.

[43] M. J. Dalby, N. Gadegaard, A. G. Curtis, and R. C. Oreffo, "Nanotopographical control of human osteoprogenitor differentiation," Current Stem Cell Research and Therapy, vol. 2, no. 2, pp. 129-138, 2007.

[44] J. M. Macak, H. Tsuchiya, A. Ghicov et al., " $\mathrm{TiO}_{2}$ nanotubes: self-organized electrochemical formation, properties and applications," Current Opinion in Solid State and Materials Science, vol. 11, no. 1, pp. 3-18, 2007. 


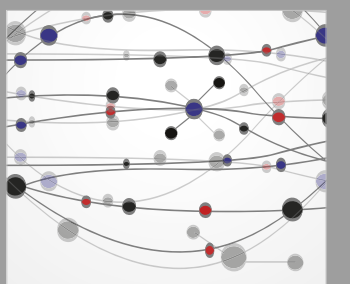

The Scientific World Journal
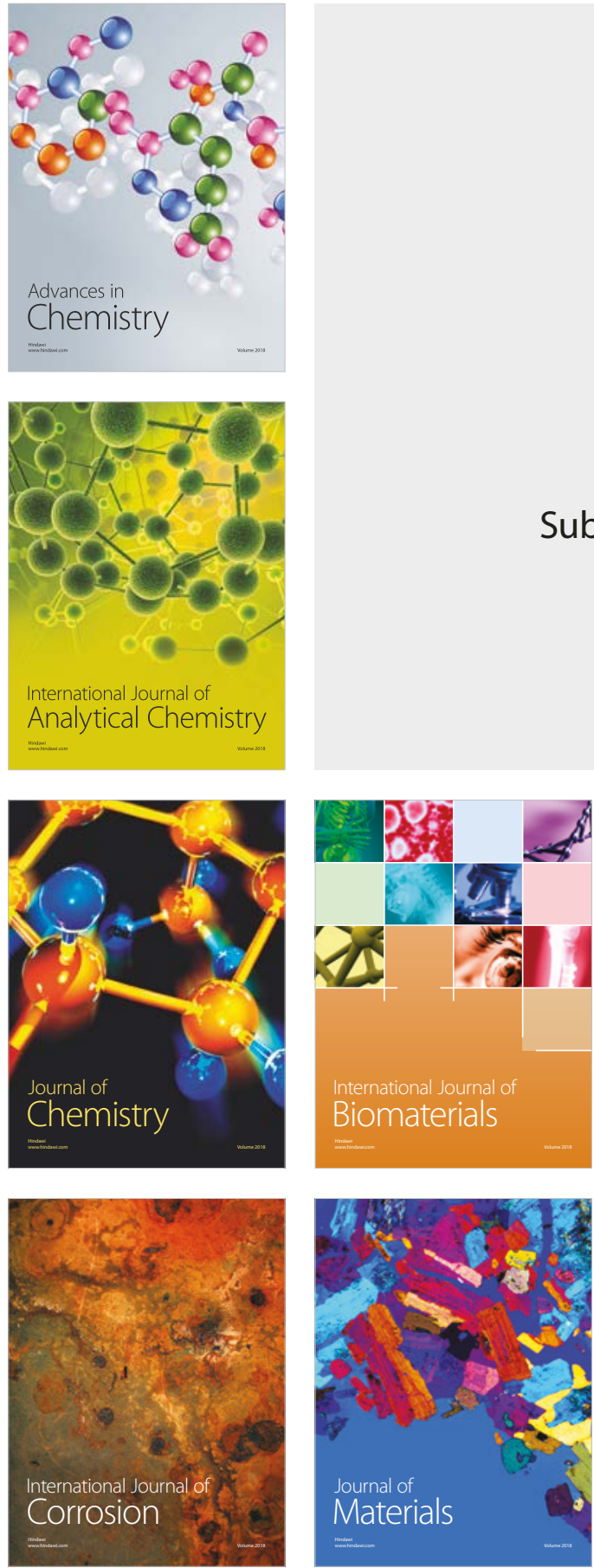

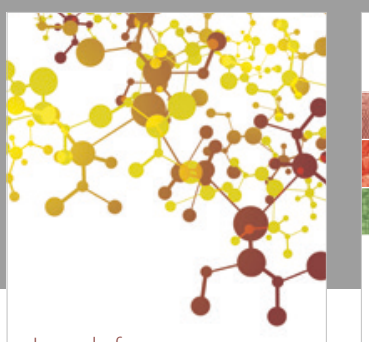

Journal of

Applied Chemistry
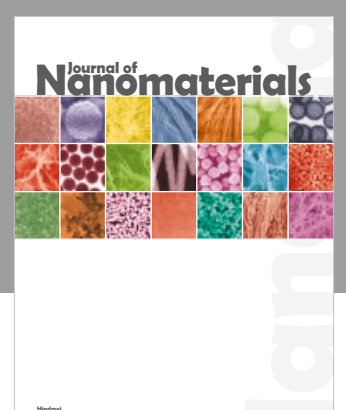

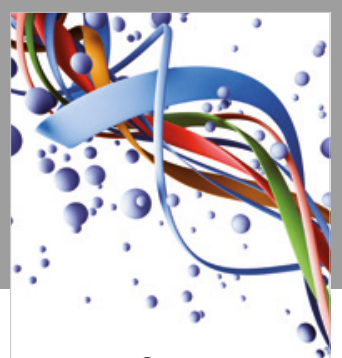

Scientifica

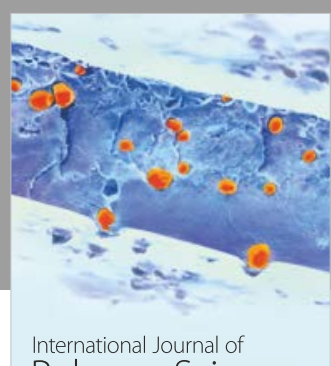

Polymer Science

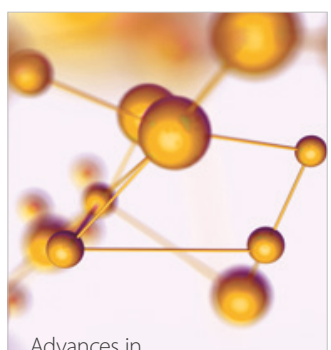

Physical Chemistry
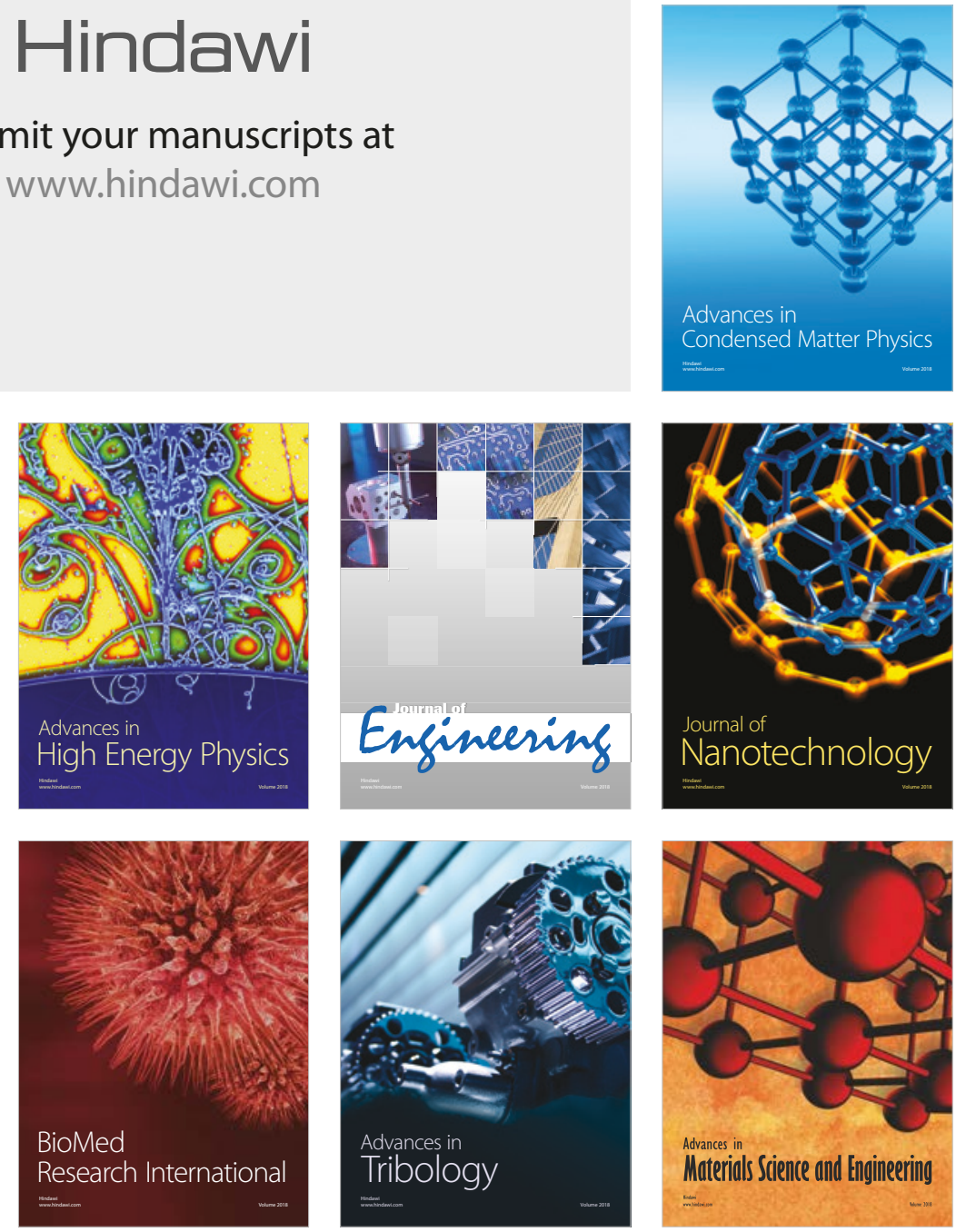